\title{
ПРОФИЛАКТИКА ПРОФЕССИОНАЛЬНЫХ ЗАБОЛЕВАНИЙ ВРАЧА-СТОМАТОЛОГА
}

\section{PREVENTION OF OCCUPATIONAL DISEASES OF A DENTIST}

\section{Orlova \\ D. Arkhangelskaya}

Summary. The professional work of medical workers is one of the most difficult, responsible and stressful types of activities, accompanied by a large mental load, which requires the doctor's concentrated attention, considerable effort and endurance, as well as a high level of efficiency. The directed improvement and further maintenance of the mental and physical abilities of a professional at an optimal level and the development of the functional stability of one's body to difficult working conditions requires special attention of all medical workers during their working life. Despite the prestige of the profession of a dentist, a large number of occupational diseases caused by the specifics and working conditions are noted in their environment. Purposefully used physical exercises adapt to the dentist's work and have significant advantages in comparison with labor movements. Along with the observance of personal hygiene and improvement of the sanitary condition of the dentist's workplaces, it is extremely important to lead a healthy lifestyle and regularly engage in physical exercise systems: running, swimming, "Scandinavian walking", dancing, performing special exercise complexes. Comprehensive education of physical qualities and the expansion of the fund of motor skills and abilities guarantees the productivity of the professional activity of a dentist.

Keywords: dentist, occupational risks, occupational diseases, personal hygiene, individual protection, physical culture; aerobic exercises; swimming; dancing; sleep.

\author{
Орлова Ирина Анатольевна \\ Преподаватель, Астраханский государственный \\ медицинский университет \\ orlow.yurij2010@yandex.ru \\ Архангельская Дарья Владимировна \\ Астраханский государственный медицинский \\ университет \\ valeriaorlova303@gmail.com
}

Аннотация. Профессиональный труд медицинских работников относится к числу наиболее сложных, ответственных и напряженных видов деятельности, сопровождающихся большой умственной нагрузкой, которая требует от врача сосредоточенного внимания, значительных усилий и выносливости, а также высокого уровня работоспособности. Направленное совершенствование и дальнейшее поддержание на оптимальном уровне психических и физических способностей профессионала и выработка функциональной устойчивости своего организма к тяжелым условиям труда требует особого внимания всех медицинских работников в течение трудовой деятельности. Несмотря на престижность профессии врача-стоматолога, в их среде отмечается большое количество профессиональных заболеваний, вызванных спецификой и условиями трудовой деятельности. Целенаправленно используемые физические упражнения адаптируют к труду стоматолога и имеют значительные преимущества в сравнении с трудовыми движениями. Наряду с соблюдением личной гигиены и улучшением санитарного состояния рабочих мест стоматолога, крайне важно вести здоровый образ жизни и регулярно заниматься физическими системами упражнений: бегом, плаванием, «скандинавской ходьбой», танцами, выполнением комплексов специальных упражнений. Всестороннее воспитание физических качеств и расширение фонда двигательных умений и навыков гарантирует продуктивность профессиональной деятельности врача-стоматолога.

Ключевые слова: стоматолог, профессиональные риски, профессиональные заболевания, личная гигиена, индивидуальная защита, физическая культура, аэробные упражнения, плавание, танцы, сон.

мость обратиться к услугам стоматолога и их количество растет с каждым годом. Стоматолог - врач, специализирующийся на проблемах с челюстно-лицевой зоной имеющий обширный спектр деятельности: профилактика; лечение; хирургическое вмешательство; протезирование; исправление прикуса и многое другое $[13,17]$.

Есть еще одна очень важная и не менее востребованная специализация врача: «стоматолог-эстет», который делает зубы красивыми, удаляя при этом все имеющиеся дефекты, осуществляет отбеливание зубов и дарит человека «голливудскую» улыбку. Следовательно, в сфере медицины профессия врача-стоматолога в настоящее 
время является актуальной, востребованной и элитной. Но и в этой ответственной и престижной профессии существуют проблемы, связанные со спецификой условий труда, влияющей на сохранение здоровья врача-стоматолога. Все болезни человека возникают из-за состояния организма, находящегося между нормой и патологией. Научные исследования и статистические данные показывают, что в России в этом состоянии находится от $50 \%$ до 80\% трудящихся разных профессий и специальностей [11].

В среде медицинских работников положение еще более катастрофично. Об этом можно судить по факту, обнародованному ВОЗ - средняя продолжительность жизни врача 54 года [8]. Авторы Максимова Е.М., Сирак С.В. утверждают, что наиболее подвержены профессиональному риску врачи-стоматологи. В целях выявления реальной картины о количестве профессиональных заболеваний ставропольскими учеными проведено масштабное анонимное анкетирование 350 врачей - стоматологов [9]. Результаты исследования показали, что 55\% опрошенных страдают заболеваниями опорно-двигательного аппарата (остеохондроз, искривление позвоночника, заболевания суставов); на патологию ЖКТ жалуются 43\% анкетированных (гастриты, холециститы); аллергические заболевания наблюдаются у $20 \%$ врачей (в связи с работой с дезинфицирующими средствами и стоматологическими материалами); заболевания органов дыхания наблюдаются у $16 \%$ респондентов, а у $8 \%$ заболевания ЛОР-органов. Более половины опрошенных (51\%) жалуются на повышенную утомляемость и раздражительность (5\%), а также на бессонницу (2\%). Повышенное артериальное давление наблюдается у 5\% анкетируемых. У абсолютного большинства врачей (88\%) выявлены сопутствующие заболевания [9].

Нередко вынужденная поза врача, по мнению Аюпова И.Ш., Максимовой Е.М., Сирак С.В., Федотовой Ю.М., Костюкова Ю.И. и др. приводит к различным заболеваниям опорно-двигательного аппарата: нарушению осанки; искривлению позвоночника; к возникновению сколиоза, остеохондроза и артрита, которые проявляются болями в мышцах, позвоночнике, в суставах, костях, изменениями в пальцевых фалангах [2;9;15,17].

При работе в положении стоя ухудшается кровообращение и возникает патология нижних конечностей (варикозное расширение вен, тромбофлебит, плоскостопие...). Из-за длительного и часто повторяющегося напряжения мышц в вынужденном положении, развивается тендовагинит (заболевание суставной сумки в местах прикрепления сухожилий), а в сочетании с болезнью Рейно (редкое заболевание артерий конечностей) это может привести к профессиональной непригодности.
По мнению авторов Максимовой Е.М., Сирак С.В., гиподинамия также является следствием вынужденной рабочей позы стоя [9].

При лечении зубов врачу от пациентов могут передаваться многие инфекционные заболевания: вирусный гепатит, герпетические и вирусные конъюнктивиты, мононуклеоз, туберкулез, токсоплазмоз, дисбактериоз, эпидемический паротит, стафилококковые, стрептококковые и другие инфекции. ВИЧ-инфекция и сифилис также могут передаваться при лечении зубов. Микроорганизмы, находящиеся в слюне, на слизистой оболочке рта при дыхании, кашле, разговоре попадают в воздух, оседают на инструментарии и оборудовании и передаются воздушно-капельным путем [19].

Из-за вдыхания мельчайшей крошки при обработке зубов и возникает риск возникновения «силикоза». Данная зубная крошка, попадая в глаза, является причиной конъюнктивита. В составленной профессиограмме видно, что на состояние здоровья врача-стоматолога оказывают вредное воздействие также наркотические и токсичные вещества, антибиотики, анестетики, полимерные материалы, употребляемые для изготовления зубных протезов и пломб, рентгеновское излучение [13].

В повседневной трудовой деятельности врачей-стоматологов вредными условиями труда являются колебания освещенности помещения и температуры воздуха в нем, что вызывает значительные нагрузки на зрительные и слуховой анализаторы, а также вибрация и шум, создаваемые высокооборотным оборудованием [14].

В этих условиях существует риск снижения слуха и остроты зрения, болей в ногах. По утверждению Аюпова И.Ш. зрительная нагрузка стоматолога относится к разряду наивысшей сложности - после десятилетнего стажа работы до 80\% врачей подвержены синдрому «сухого глаза» [2].

На применение очков для врача необходимо остановиться подробнее. С целью профилактики термических и механических травм служат защитные очки и экран, предохраняющие слизистую оболочку глаза от попадания биоматериала и агрессивных химических веществ. Для защиты сетчатки глаз при работе с гелиолампами и лазерными аппаратами необходимы очки со светофильтрами [13].

С целью профилактики негативных воздействий генераторов вибрации и шума необходимо использовать перчатки и обувь, гасящие вибрацию, а также организовывать достаточную шумоизоляцию рабочего места $[9 ; 13]$. 
Чтобы обеспечить необходимое санитарное состояние рабочих мест врача-стоматолога необходимо проводить влажную гигиеническую уборку, проветривание или кондиционирование помещений, включая устройства вытяжной вентиляции, обеспечивающих удаление пыли, газов и паров непосредственно с мест их образования. Следует отметить, что температура воздуха рабочего помещения должна быть 18-20 градусов, а освещение быть естественным. Также крайне важным является соблюдение личной гигиены, использование средств индивидуальной защиты от вредных профессиональных факторов: специальной одежды, перчаток, очков, шапочек и других защитных приспособлений [13].

В своей работе врачу необходимо избегать напряженной и некомфортной позы собственного тела, приняв наиболее удобное и эргономически выгодное положение собственного тела, подготовив для каждого пациента оптимальное положение стоматологического кресла.

Важным средством профилактики профессиональных заболеваний врачей-стоматологов и улучшением состояния их здоровья является физическая культура и здоровый образ жизни. Подавляющее большинство врачей поддерживают этот тезис, но нередко сами его игнорируют. Необходимо вернуться к результатам исследования ставропольских ученых, на которые мы опирались в начале нашей публикации. Показательной является следующая статистика: вредным привычкам подвержены 55\% врачей, хотя каждый пятый из их числа от этих привычек стараются избавиться. Лишь 10\% опрошенных регулярно занимаются физической культурой, и только 6\% делают утреннюю гимнастику [9].

Подобные статистические данные подтверждает и целый ряд других исследований авторов Косарева В.В., Бабанова С.А., Лебедева М., Федотовой Ю.М. и Костюковой Ю.И. [7;8;15]. Следовательно, можно сделать вывод, что забота о собственном здоровье и здоровом образе жизни для многих врачей не является первостепенной.

Качественное и эффективное лечение пациентов зависит не только от профессионализма врача и материально-технического обеспечения кабинета, и лаборатории, но, прежде всего, от состояния его здоровья. Профессиональные заболевания, возникающие в процессе трудовой деятельности стоматолога, диктуют необходимость комплексного здоровье сберегающего подхода, который включает в себя регулярные (ежегодные) медицинские осмотры, флюорографические исследования, гигиену труда и отдыха, соблюдение мер техники безопасности, потребность в здоровом образе жизни, включая регулярные занятие физической культурой и спортом.
Анализ профессиограммы показывает, что успешная профессиональная деятельность врача-стоматолога предъявляет повышенные требования к физическим качествам выносливости, силы, координации движений (мелкая моторика рук, дифференцировка мышечных усилий). Профессионально важным для врача являются также долговременная память (зрительная, слуховая, обонятельная, сенсорная), высокий уровень концентрации внимания, а также зрение и слух [3;13].

Эксперименты американского нейропсихолога К. Постала позволили установить, что в головном мозге взрослого человека образуются новые нейроны и способствуют этому активные аэробные упражнения. И если подобные тренировки продолжаются до пота в течение 30-40 минут, то генерируются новые мозговые клетки. Этот научный факт подтверждают и шведские нейробиологи, которые считают, что в этом «заслуга» стволовых клеток, способствующих освоению новых знаний даже в солидном возрасте [16].

Занятия физическими упражнениями позволяют держать себя в тонусе до преклонных лет, но при этом важен настрой и собственная мотивация к сохранению своего здоровья для активного профессионального долголетия.

Ученые считают, что наиболее оптимальными являются кардио-тренировки и интенсивные интервальные тренировки, совершенствующие выносливость и дыхательную систему - бег, быстрая ходьба, плавание, велопробеги. В качестве примера врачам-стоматологам можно предложить использовать бег на предельной скорости в течение 30 секунд, а затем ходьба со скоростью примерно 6 км\час. Кардионагрузки по 30-40 минут пять раз в неделю делают человека на 9 лет моложе своего биологического возраста. В оставшиеся два дня недели рекомендуется выполнять силовые упражнения по полчаса в день (отжимания от пола, приседания, упражнения «планка», жим лёжа с умеренным весом утяжеления, гантели).

Следует отметить, что в настоящее время значительно увеличилось количество поклонников «скандинавской ходьбы», которая вовлекает в работу до 90\% мышечных групп человека и облегчает при этом при помощи лыжных палок нагрузку с суставов ног. Этот факт профессионально важен для врачей-стоматологов, особенно людей старшего возраста. По мнению О. Сайкса Олифера танцы также являются эффективным средством снятия эмоциональной напряженности, улучшения настроения и эффективной активности мозга, совершенствования внимания и памяти. За счет вариативности двигательных движений, динамичности, балансировки и равновесия танцы оказывают даже более существенные изменения в гиппокампе, чем при занятиях фитнесом, циклически- 
ми локомоциями (бег, ходьба, езда на велосипеде...) при том же объеме времени затраченного на занятие [12].

На занятии плаванием необходимо остановиться подробнее, так как этот вид спорта известен не только как средство совершенствования физических качеств и функций, но и способствует профилактике и лечению многих заболеваний. Как утверждают Доронцев А.В. и Батыров Э.М., нахождение в водной среде почти исключает работу скелетных мышц, что приводит к возможности их максимального расслабления [5,6]. Нагрузка на позвоночник уменьшается и это служит благоприятным фактором для лечения остеохондроза, радикулита, спондилита, сколиоза. Занятия в бассейне способствуют вылечиванию различных травм, вывихов, растяжений связок. Авторы Навратил М., Кадлец К и Даумс отмечают, что горизонтальное положение тела при плавании значительно облегчает работу сердца, так как в этих условиях отсутствует сила тяжести, являющаяся препятствием для продвижения крови по венам нижних конечностей, что является профилактикой варикозного расширения вен [10].

Также плавание является эффективным средством для улучшения подвижности в суставах и совершенствования координации движений. Плавание - оптимальный вид циклического спорта для совершенствования выносливости и улучшения когнитивной работоспособности врача-стоматолога [5].

Выполнение комплексов упражнений для профилактики профессиональных болезней врача должно быть обязательным и ежедневным. Комплексы необходимо выполнять в положении стоя и с широкой амплитудой, с обязательным выполнением упражнений для мышц ног. Эти упражнения не только способствуют улучшению кровоснабжения всего организма, но и ликвидируют застойные явления венозной крови в области малого таза и нижний конечностей. Обязательно использовать в таких комплексах наклоны в разные стороны, прогибы туловища назад для снятия нагрузки с позвоночника и улучшения осанки. Рекомендуются также потягивания, встряхивания рук и кистей, повороты плеч и головы.

Активными физическими упражнениями и профилактическими мерами необходимо заниматься 10-15 минут ежедневно и в любое свободное от работы время. Для профилактики практически всех профессиональных заболеваний, включая эмоциональный стресс и профессиональное выгорание, необходимо выполнение дыхательных упражнений с задержкой дыхания на вдохе на 12-15 секунд.

Расстройство сна, долгое засыпание, поверхностный и прерывистый сон, преждевременное пробуждение негативно сказывается на работоспособности врача, настроении, здоровье и тем самым на ухудшение качества жизни. Для быстрого и надежного засыпания можно рекомендовать «метод 4-7-8» [13]. Этот метод, используемый ночами для расслабления и профилактики стресса, прошел многовековое испытание временем. Суть метода в следующем: перед засыпанием нужно успокоиться и сосредоточить внимание на дыхании. Дыхание осуществлять следующим образом: вдох сделать на четыре счета; задержать дыхание на протяжении семи счетов; произвести выдох на восемь счетов. Повторив эту дыхательную гимнастику, вы почувствуете дрёму, и незаметно для себя уснете.

Выполнение рекомендаций нашей публикации поможет поддерживать качество жизни врача-стоматолога на должном уровне и продлить профессиональное долголетие.

\section{ЛИТЕРАТУРА}

1. Антонова Н. Николас Тульп, врач, интересные люди, биография. /Наталия Н. Антонова. Интересные люди. 11 октября 2016 (Электронный ресурс) httрs:// www.myjane.ru/articles/text/?id17664 Дата обращения 3.10 .2021

2. Аюпов И.Ш. Профессиональные заболевания врача-стоматолога. Методы профилактики.//Международный студенческий научный вестник. - 2016. № 2.- - c. 37-41

3. Врач — стоматолог (профессиограмма) /Л.П. Яролович. (Электронный ресурс) kem.by. Copyright @ 2016 Журнал «Keм Быть?». All Rights Reserved. https:// www.Kem.bylprofalrabota-kak-estetigheskoe-udovolstvie Дата обращения 3.10.2021

4. Все о профессии врача / Плотникова М. 2010 (Электронный ресурс) https://medru.su/professii/specialnost-vrach.htme Дата 0бращения 3.10 .2021

5. Доронцев А.В., Батыров Э.М. Формирование навыков профилактики заболеваний средствами физической культуры у студентов медицинских вузов.Астрахань. - 2009.- 172 c.

6. Доронцев А.В. Оценка факторов риска развития дезадаптивных реакций на физическую нагрузку различной направленности у мужчин среднего возраста/ А.В. Доронцев, А.А. Светличкина // Человек. Спорт. Медицина. - 2020.— Т. 20., № 1. — С. 135-141

7. Как уснуть за одну минуту? Эффективный способ, проверенный временем / В. Кулиев. 19.09.2021. (Электронный pecypc) https://zen.yandex.ru/media/ likeworkout/kak-usnut-za-odin... Дата обращения 3.10.2021

8. Косарев В.В., Бабанов С.А. Профессиональная заболеваемость медицинских работников//медицинский альманах. — 2010. — № 3. Изд-во «ЩЩЩ Ремедиум приволжье».- - с. 29 
9. Лебедев М. Врачи живут на 20 лет меньше.— Версия. Общество.— № 37 от 27.09.2021 /M. Лебедев (Электронный pecypc) https://versia.ru//vrachizhuvut-na-20let-menshe-svoix-pacientov Дата обращения 3.10.2021

10. Максимова Е.М., Сирак С.В. Анализ рисков и мер по профилактике профессиональных болезней врачей-стоматологов // Фундаментальные исследования. — 2013.— № 5 (часть 2) - с. 319-323

11. Навратил М., Кадлец К., Даумс. Патофизиология дыхания [текст]: М., «Медицина», 1967, с. 43

12. 0. Сайкс Олифер. Музыкоорелия. Изд-во «АSTPablishers», 2017. - $448 \mathrm{м}$.

13. Оценка профессионально-прикладной физической культуры студентов медицинского вуза / А.В. Доронцев, Э.А. Аленуров, В.И. Шарагин, Э.Ш. Петина // Теория и практика физической культуры.— 2019.—№ 5.— С. 31-33.

14. Профессиограмма. Врач-стоматолог. Интерактивный портал Агентства труда и занятости населения Красноярского края. 30.12 .2016 (Электронный ресурс) https://trud.Krsktate.ru/professiograms/detail/23db2ceo-1af8-eb2-ae01-b2d2a8672847 Дата обращения 3.10.2021.

15. Светличкина, А.А. Особенности планирования уровня физических нагрузок у студентов специальной медицинской группы «А» имеющих сочетанные заболевания сердечно — сосудистой системы и вертебральной области / А.А. Светличкина, А.В. Доронцев// Ученые записки университета им. П.Ф. Лесгафта. 2020. № 1 (179). С. 245-250.

16. Семенова Е. Мне всё равно: 99\% врачей профессионально выгорают на работе. LIFF Медицинская Россия. 25.12.2017 (Электронный ресурс) https:// medrussia.org/12325mnevsu0-ravno/ Дата обращения 3.10.2021

17. Федотова Ю.М., КостЮкова Ю.И. ПРОФЕССИОНАЛЬНЫЕЗАБОЛЕВАНИЯ ВРАЧА-СТОМАТОЛОГА // Научное обозрение. МедИцинские науки. — 2017. — № 2. C. 19-21; URL: https://science-medicine.ru/ru/article/view?id=966 (дата обращения: 03.10.2021).

18. Zavalishina, S. Yu., Pravdov D.M., Bakulina T.D., Eremin M.V., Rysakova 0.G., Dorontsev A.V. Strengthening the general functional capabilities of the body in the conditions of a feasible increase in muscle activity after intervention on the heart. Biomedical and Pharmacology Journal. 2020; 13(2): 597-602.

19. Karpov V. Yu., Zavalishina S. Yu., Dorontsev A.V., Voronova N.N., Shulgin V.I., Kozyakov R.V. Influence of regular feasible physical activity on the platelets functional activity of the second mature age people. Systematic Reviews in Pharmacy. 2020; 11(8): 439-445.

( О Орлова Ирина Анатольевна ( orlow.yurij2010@yandex.ru ), Архангельская Дарья Владимировна ( valeriaorlova303@gmail.com ).

Журнал «Современная наука: актуальные проблемы теории и практики»

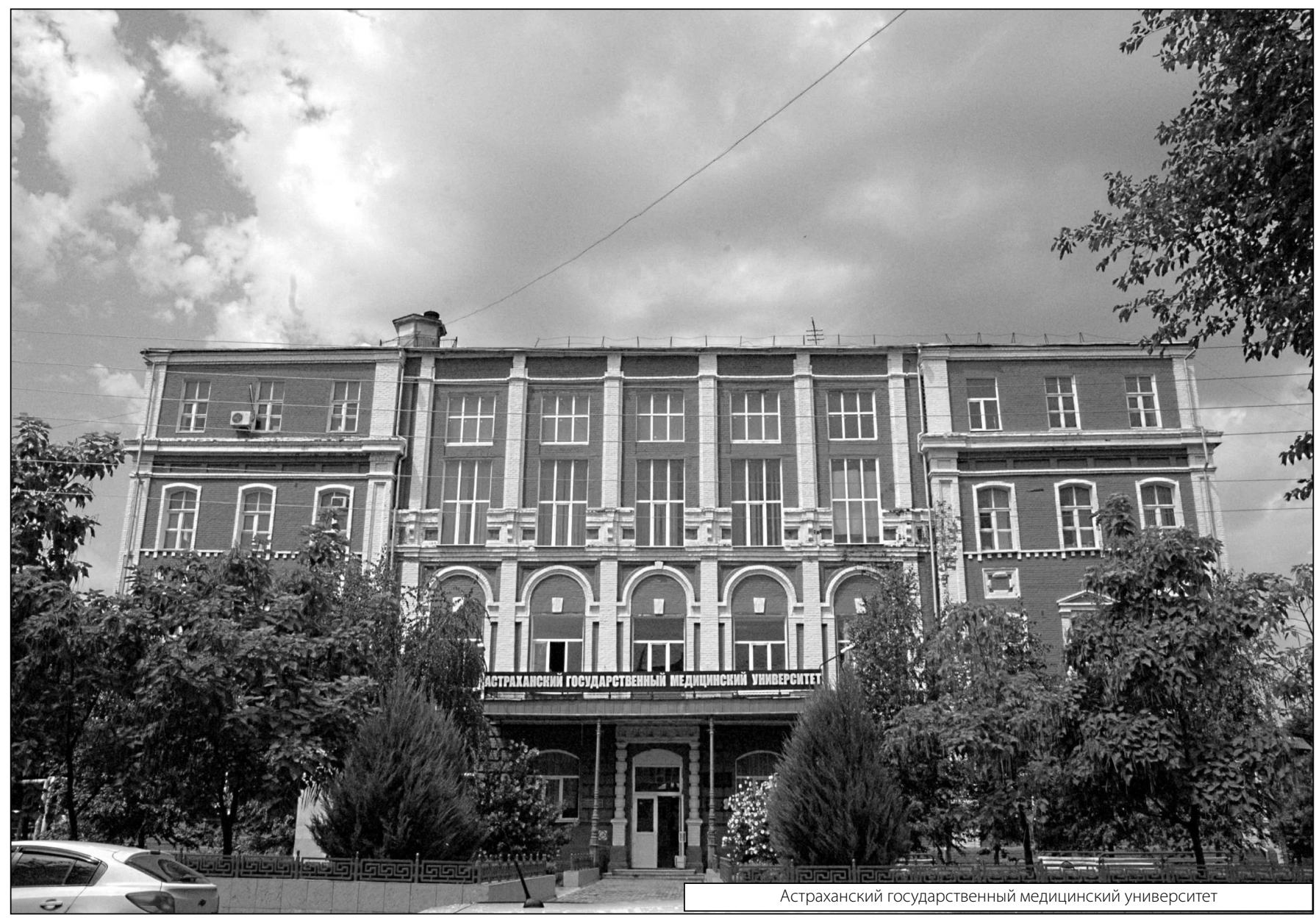

